\title{
Physical Properties of ZnO Thin Films Codoped with Titanium and Hydrogen Prepared by RF Magnetron Sputtering with Different Substrate Temperatures
}

\author{
Fang-Hsing Wang, ${ }^{1}$ Jen-Chi Chao, ${ }^{1}$ Han-Wen Liu, ${ }^{1}$ and Tsung-Kuei Kang ${ }^{2}$ \\ ${ }^{1}$ Department of Electrical Engineering and Graduate Institute of Optoelectronic Engineering, National Chung Hsing University, \\ Taichung 40227, Taiwan \\ ${ }^{2}$ Department of Electronic Engineering, Feng-Chia University, Taichung 40724, Taiwan
}

Correspondence should be addressed to Fang-Hsing Wang; fansen@dragon.nchu.edu.tw

Received 11 November 2014; Accepted 22 December 2014

Academic Editor: Yibing Cai

Copyright (C) 2015 Fang-Hsing Wang et al. This is an open access article distributed under the Creative Commons Attribution License, which permits unrestricted use, distribution, and reproduction in any medium, provided the original work is properly cited.

\begin{abstract}
Transparent conducting titanium-doped zinc oxide (TZO) thin films were prepared on glass substrates by RF magnetron sputtering using $1.5 \mathrm{wt} \% \mathrm{TiO}_{2}$-doped $\mathrm{ZnO}$ as the target. Electrical, structural, and optical properties of films were investigated as a function of $\mathrm{H}_{2} /\left(\mathrm{Ar}+\mathrm{H}_{2}\right)$ flow ratios $\left(R_{H}\right)$ and substrate temperatures $\left(T_{S}\right)$. The optimal $R_{H}$ value for achieving high conducting TZO:H thin film decreased from $10 \%$ to $1 \%$ when $T_{S}$ increased from RT to $300^{\circ} \mathrm{C}$. The lowest resistivity of $9.2 \times 10^{-4} \Omega$-cm was obtained as $T_{S}=100^{\circ} \mathrm{C}$ and $R_{H}=7.5 \%$. X-ray diffraction patterns showed that all of TZO:H films had a hexagonal wurtzite structure with a preferred orientation in the (002) direction. Atomic force microscopy analysis revealed that the film surface roughness increased with increasing $R_{H}$. The average visible transmittance decreased with increasing $R_{H}$ for the RT-deposited film, while it had not considerably changed with different $R_{H}$ for the $300^{\circ} \mathrm{C}$-deposited films. The optical bandgap increased as $R_{H}$ increased, which is consistent with the Burstein-Moss effect. The figure of merits indicated that $T_{S}=100^{\circ} \mathrm{C}$ and $R_{H}=7.5 \%$ were optimal conditions for TZO thin films as transparent conducting electrode applications.
\end{abstract}

\section{Introduction}

Transparent conducting oxide (TCO) films were widely used in optoelectronic devices such as low-emissivity windows, electromagnetic shielding, gas sensors, information displays, and photovoltaic cells [1-5]. Indium tin oxide (ITO) is a commonly used TCO at present, but indium is a rare metal and with toxicity. Zinc oxide $(\mathrm{ZnO})$ is regarded as a promising TCO material due to its advantages such as nontoxicity, abundance, and high stability in hydrogen plasma [1]. Since undoped $\mathrm{ZnO}$ films have an unstable electrical conductivity, group IIIA element ( $\mathrm{Al}, \mathrm{Ga}$, or $\mathrm{In}$ ) doped $\mathrm{ZnO}$ thin films have been widely studied to enhance the film conductivity [3-8]. A few reports suggest that $\mathrm{Ti}$ is a possible dopant for $\mathrm{ZnO}$ films because $\mathrm{Ti}$ is a quadrivalent cation and has a radius of $68 \mathrm{pm}$ which is close to that of $\mathrm{Zn}$ (74 pm) [9-11]. The quadrivalent cation may provide one more valence than the trivalent cation as it substitutes $\mathrm{Zn}$ in $\mathrm{ZnO}$ films. TZO thin films have been prepared by several techniques, including radio frequency (RF)/DC sputtering [11-13], chemical vapor deposition (CVD) [14], and sol-gel process [15]. Among these methods, sputtering has advantages such as good uniformity, high process controllability, and large-area deposition and has been widely used. Lin et al. investigated the effect of $\mathrm{Ti}$ content on the properties of Ti-doped $\mathrm{ZnO}$ (TZO) films [9]. Chung et al. investigated the effect of the $\mathrm{TiO}_{2}$ content of the target, the working pressure, and the substrate temperature on the properties of $\mathrm{TiO}_{2}$-doped $\mathrm{ZnO}$ films [10]. In our previous research, effects of thickness and plasma treatment on the properties of Ti-doped $\mathrm{ZnO}$ films had been investigated $[11,16]$.

Recently, the density functional theory proposed by van de Walle shows that hydrogen atoms can act as donors 
and thus enhance electrical conductivity of $\mathrm{ZnO}[17,18]$. In addition, experimental investigates on effects of in situ hydrogen doping on $\mathrm{ZnO}$-related films have been performed $[5,12,19,20]$. Lee et al. reported that hydrogen might act like an anionic dopant by binding with oxygen in $\mathrm{Al}$-doped $\mathrm{ZnO}$ (AZO) films [19]. Das and Ray investigated AZO films prepared by RF magnetron sputtering under $\mathrm{Ar}+\mathrm{H}_{2}$ ambient and concluded that the low resistivity $\left(4.5 \times 10^{-4} \Omega-\mathrm{cm}\right)$ was achieved at the substrate temperature of $300^{\circ} \mathrm{C}$ with the $\mathrm{H}_{2} /\left(\mathrm{Ar}+\mathrm{H}_{2}\right)$ flow ratio of $10 \%$ [20].

In this study, TZO thin films were prepared by RF magnetron sputtering under various $\mathrm{H}_{2} /\left(\mathrm{Ar}+\mathrm{H}_{2}\right)$ ratios in sputtering ambient at different substrate temperatures. The temperature dependent effects of hydrogen doping on the electrical, structural, and optical properties of TZO thin films were investigated.

\section{Experimental Procedures}

TZO powder $\left(\mathrm{ZnO}=98.5 \mathrm{wt} \%, 99.999 \%\right.$ purity; $\mathrm{TiO}_{2}=$ $1.5 \mathrm{wt} \%, 99.99 \%$ purity) was calcined at $1400^{\circ} \mathrm{C}$ to prepare ceramic targets with a 2 inch diameter. Before the deposition process, the glass substrates were cleaned ultrasonically with isopropyl alcohol and deionized water and subsequently dried under a blown nitrogen gas. TZO thin films with a thickness of about $330 \mathrm{~nm}$ were deposited on $30 \mathrm{~mm} \times$ $30 \mathrm{~mm} \times 2 \mathrm{~mm}$ Corning 1737 glass substrates by using a Syskey $13.56 \mathrm{MHz}$ RF magnetron sputtering system at a constant power of $100 \mathrm{~W}$. The working distance was $10 \mathrm{~cm}$. The base pressure of the deposition chamber was below $5 \times$ $10^{-6}$ Torr and the working pressure was maintained at $5 \times$ $10^{-3}$ Torr in $\mathrm{Ar}$ or $\mathrm{Ar}+\mathrm{H}_{2}$ mixture gas with a constant flow rate of $20 \mathrm{sccm}$. A series of TZO films were prepared with varying the $\mathrm{H}_{2} /\left(\mathrm{Ar}+\mathrm{H}_{2}\right)$ flow ratio from $0 \%$ to $15 \%$ at various substrate temperatures ranging from room temperature (RT) to $300^{\circ} \mathrm{C}$. The substrate holder rotated at a constant speed of $35 \mathrm{rpm}$ during sputtering to obtain a better film uniformity.

Film thickness was measured using a spectroscopic ellipsometer (nanoview, SEMF-100) and confirmed by field emission scanning electron microscopy (FE-SEM) (JEOL, JSM6700). Crystallographic phases and crystalline quality of films were analyzed using X-ray diffraction (XRD) (PANalytical, $18 \mathrm{~kW}$ rotating anode X-ray generator, Japan) with $\mathrm{Cu}-\mathrm{K} \alpha$ radiation $(\lambda=0.154056 \mathrm{~nm})$ in the conventional $\vartheta-2 \vartheta$ mode. Morphology of films was observed using FE-SEM and atomic force microscopy (AFM) (Digital Instrument, NS4/D3100CL/Multimode). Electrical resistivity, carrier concentration, and Hall mobility were determined by a fourpoint probe (Napson RT-70/RG-5) and Hall-effect measurements (Ecopia, HMS-3000) using the van der Pauw method at a magnetic field of $0.55 \mathrm{~T}$. The optical transmittance spectrum was measured using a UV/VIS/IR spectrophotometer (Jasco, V-570) in the $220-2500 \mathrm{~nm}$ wavelength range. The chemical bonding states of elements in TZO films were investigated using an X-ray photoelectron spectroscopy (XPS) (ULVAC-PHI, PHI 5000 Versaprobe). All measurements were performed at RT.

\section{Results and Discussion}

Figure 1 exhibits the variation in the resistivity, Hall mobility, and carrier concentration of TZO thin films with $\mathrm{H}_{2} /(\mathrm{Ar}+$ $\mathrm{H}_{2}$ ) gas flow ratio $\left(R_{H}\right)$ and substrate temperature $\left(T_{S}\right)$. At the lower $T_{S}$ of $\mathrm{RT}-100^{\circ} \mathrm{C}$, it was found that the electrical properties of TZO films strongly depended on $R_{H}$. As $R_{H}$ varied from $0 \%$ to $15 \%$, the resistivity of RT-deposited films ranged between 1.08 and $1.82 \times 10^{-3} \Omega$-cm, which differed by near three orders of magnitude. However, the dependence of the electrical properties on $R_{H}$ became relatively small as $T_{S}$ increased to above $200^{\circ} \mathrm{C}$. The resistivity of films deposited at $300^{\circ} \mathrm{C}$ ranged between $3.47 \times 10^{-3}$ and $2.07 \times 10^{-3} \Omega-\mathrm{cm}$. Besides, the resistivity of TZO thin films initially decreased with increasing $R_{H}$ and then increased with increasing $R_{H}$ despite substrate temperatures. The optimal electrical property is obtained with the lowest film resistivity. The lowest resistivities of TZO thin films deposited at RT, $100^{\circ} \mathrm{C}$, $200^{\circ} \mathrm{C}$, and $300^{\circ} \mathrm{C}$ were achieved when $R_{H}$ were $10 \%, 7.5 \%$, $5 \%$, and $1 \%$, respectively. These results reveal that electrical properties of TZO: $\mathrm{H}$ thin films strongly depend on $T_{S}$ as well as hydrogen doping effect. Effectiveness of hydrogen doping in TZO films decreases with increasing $T_{S}$. Among these four $T_{S}$ conditions, the lowest resistivity of $9.2 \times 10^{-4} \Omega-\mathrm{cm}$ was achieved for the film deposited at $100^{\circ} \mathrm{C}$ with $R_{H}=7.5 \%$ and accompanied by a carrier concentration of $8.49 \times 10^{20} \mathrm{~cm}^{-3}$ and a mobility of $7.95 \mathrm{~cm}^{2} / \mathrm{V}$-s. The decrease in resistivity can be due to the increase in carrier concentration $(n)$ and/or in mobility $(\mu)$. From Figure 1, it was found that the lower- $T_{S}$ deposited TZO films had more $n$ and $\mu$ dependence on $R_{H}$. In addition, the decrease in film resistivity was mainly due to the increase in carrier concentration. For the $100^{\circ} \mathrm{C}$-deposited films, the carrier concentration increases by more than 2 orders of magnitude, that is, from $7.5 \times 10^{18}\left(R_{H}=0 \%\right)$ to $8.5 \times$ $10^{20} \mathrm{~cm}^{-3}\left(R_{H}=7.5 \%\right)$, while the Hall mobility increases only by about 2.6 times of magnitude (from 3.6 to $9.3 \mathrm{~cm}^{2} / \mathrm{V}-\mathrm{s}$ ). For the $300^{\circ} \mathrm{C}$ deposited films, the decrease of the resistivity $\left(R_{H}=1.0 \%\right)$ completely results from the increase of the carrier concentration even though the Hall mobility decreases. These results reveal that the hydrogen doping is more effective in generating free carriers at a lower substrate temperature.

As mentioned above, the variation trends of the carrier concentration and the Hall mobility with different $R_{H}$ depend on the $T_{S}$. In the earlier literatures, Bikowski and Ellmer performed the $\mathrm{ZnO}: \mathrm{Al}$ and $\mathrm{ZnMgO}$ :Al film depositions in $\mathrm{Ar} / \mathrm{H}_{2}$ ambient $\left(R_{H}=0-10 \%\right)$ at $\mathrm{RT}$ and $300^{\circ} \mathrm{C}$ [21]. Their results showed that the resistivity decreased by about 2 orders of magnitude for the RT deposition, while resistivity increased for the $300^{\circ} \mathrm{C}$ depositions with increasing hydrogen flow. Kim et al. performed the $\mathrm{ZnO}: \mathrm{Ga}$ film depositions at $80-270^{\circ} \mathrm{C}$ and observed the optimal resistivities obtained with $R_{H}=6 \%$, $10 \%$, and $0 \%$ at $T_{S}=80^{\circ} \mathrm{C}, 160^{\circ} \mathrm{C}$, and $270^{\circ} \mathrm{C}$, respectively [22]. Their minimum resistivities and corresponding $R_{H}$ values are comparatively different from our results due to different doped cation and deposition parameters. van de Walle theoretically studied the role of hydrogen in $\mathrm{ZnO}$ through a first principles investigation, based on density functional theory, and produced strong evidence that hydrogen could 


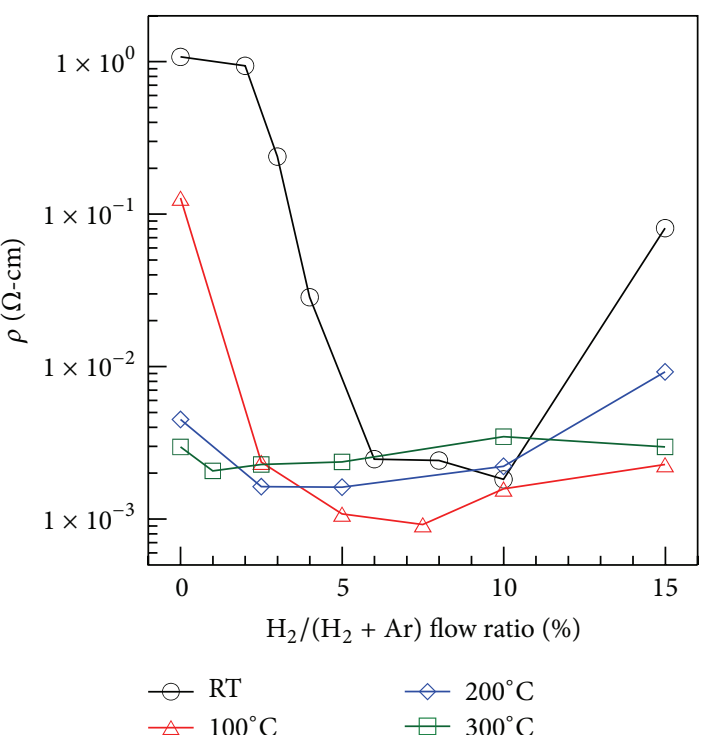

(a)

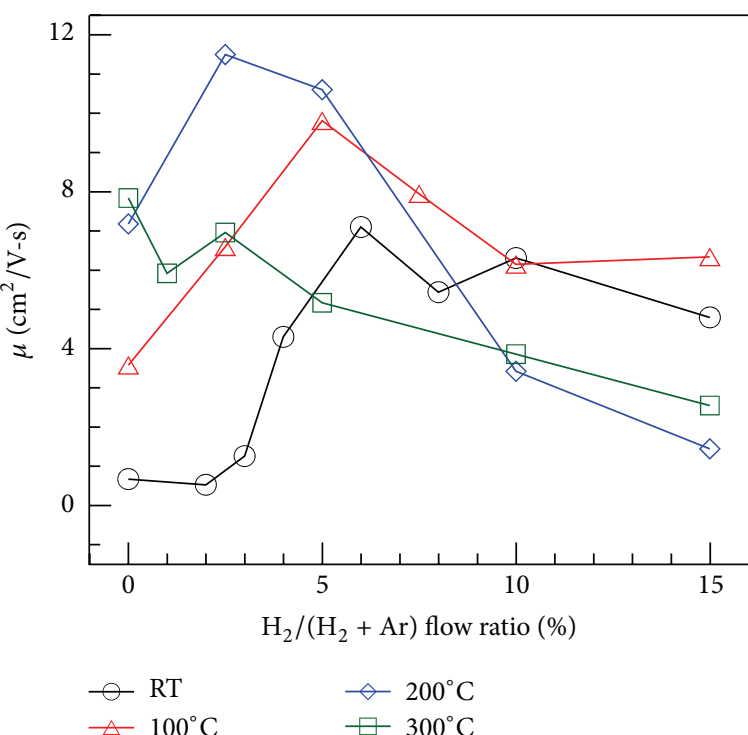

(b)

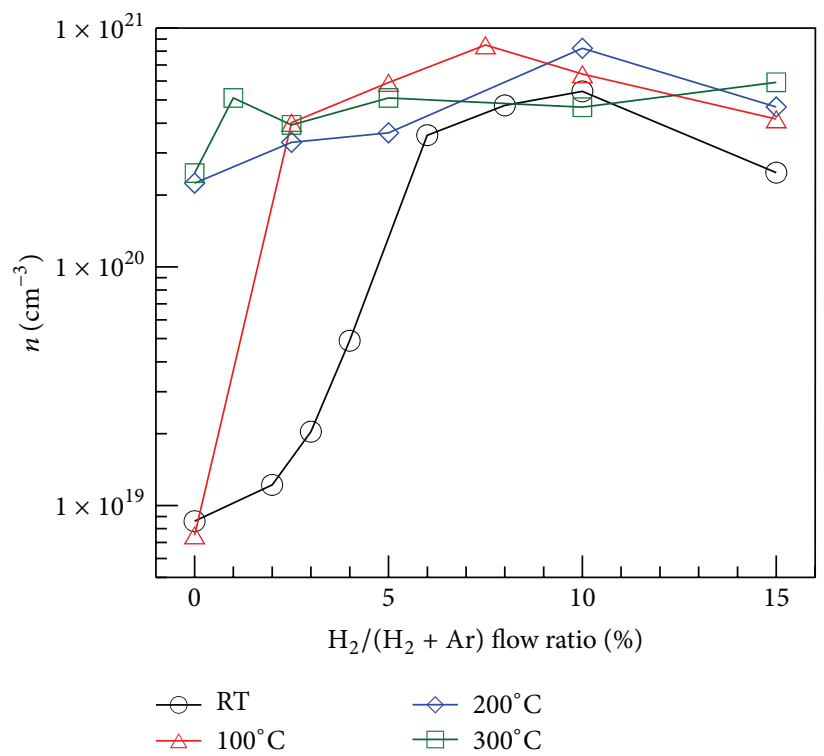

(c)

Figure 1: Dependence of the (a) resistivity, (b) Hall mobility, and (c) carrier concentration of TZO thin films on $\mathrm{H}_{2} /\left(\mathrm{Ar}+\mathrm{H}_{2}\right)$ flow ratio and substrate temperature.

incorporate in high concentrations and acted as a shallow donor to enhance film conductivity $[17,18]$. In this work, the lower deposition temperature causes worse crystallinity and more defects in the film. Thus, effectiveness of hydrogen doping can be enhanced at low $T_{S}$ by inserting into interstitial $\left(\mathrm{H}_{i}\right)$ or in oxygen bond-center $\left(\mathrm{H}_{\mathrm{O}}\right)$ lattice sites. Besides, it is possible that hydrogen extracts oxygen from thin films, causing the formation of oxygen vacancy and interstitial zinc atoms to increase the carrier concentration [23, 24]. With further increasing $R_{H}$ beyond the abovementioned optimal value, film resistivity started to increase due to the decreased Hall mobility. R. B. H. Tahar and N. B. H. Tahar indicated that the mobility was dominant by neutral and ionized impurity scattering in $\mathrm{ZnO}$ films [25]. Here, excess hydrogen doping may generate more defects and free carriers, which enhance carrier scattering phenomenon, thus causing the decrease of Hall mobility. It is also noted that Hall mobility has a maximum value at the middle substrate temperature $\left(200^{\circ} \mathrm{C}\right)$. Lin et al. proposed that oxygen atoms tended to create more neutral impurity scattering centers in the low and high temperature range, and hence Hall mobility was degraded [26].

Figure 2 shows the relationship between Hall mobility $(\mu)$ and carrier concentration $(n)$ for the TZO thin films prepared at RT and $300^{\circ} \mathrm{C}$. For the films deposited at the low temperature (RT), the Hall mobility increased with 


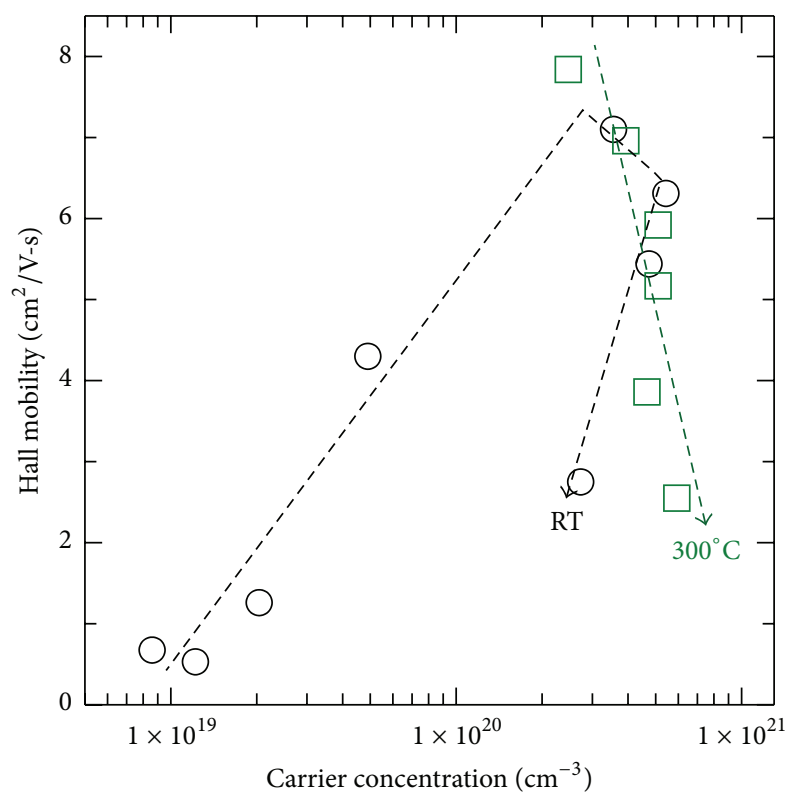

FIgURE 2: Relationship between Hall mobility $(\mu)$ and carrier concentration $(n)$ for TZO thin films prepared at RT and $300^{\circ} \mathrm{C}$.

the carrier concentration as $R_{H}$ ranges from 0 to $6 \%$. This increase suggests that carrier transport in the films with less than $6 \% R_{H}$ (i.e., $n<2 \times 10^{20} \mathrm{~cm}^{-3}$ ) is limited by grain boundary scattering, which assumes that potential barriers at grain boundaries limit the carrier transport significantly. As the $R_{H}$ increased from $6 \%$ to $8 \%$, the Hall mobility decreased with the carrier concentration, revealing that ionized impurity scattering dominated due to the increase of electron scattering centers [27]. This behavior is consistent with the theoretical prediction by Brooks-Herring theory [28]. With further increasing $R_{H}$ more than $8 \%$ (i.e., $n>6 \times$ $10^{20} \mathrm{~cm}^{-3}$ ), both the mobility and the carrier concentration decreased, indicating that grain boundary scattering became prominent in carrier transport processes. It is thought that high hydrogen contents restrain grain growth, resulting in poor crystallinity and small grain size. The Hall mobilitycarrier concentration relationship has also been reported in sputtered $\mathrm{AZO}$ and GZO thin films [21, 22]. Electron transport mechanism depends on carrier concentration and is explained by a combined model of ionized-impurity scattering or grain barrier scattering for the low-temperature deposited films. The carrier concentration of the $300^{\circ} \mathrm{C}$ deposited films ranged between 2 and $6 \times 10^{20} \mathrm{~cm}^{-3}$ and the decrease of the Hall mobility is accompanied with the increase of the carrier concentration with increasing $R_{H}$, indicating the ionized impurity scattering dominates at the high substrate temperature. Bikowski and Ellmer have revealed that $300^{\circ} \mathrm{C}$-deposited AZO films exhibited the ionized impurity scattering [21], while Kim et al. have related $270^{\circ} \mathrm{C}$-deposited GZO films to grain barrier scattering [22]. The difference between this study and earlier research is not clear and may be due to different doped cations and process parameters.

XPS analysis was executed to explore the film composition and chemical states of elements in TZO thin films for clarifying the conducting mechanism. Figure 3(a) shows the XPS spectrum of the RT-deposited TZO thin film with $R_{H}=$ $0 \%$. Observed characteristic peaks in Figure 3(a) indicated that Ti existed in the thin films. The peaks located at around $530 \mathrm{~nm}$ are assigned to $\mathrm{O}$ 1s. Figures 3(b) and 3(c) show the spectra of $\mathrm{O}$ 1s for RT-deposited TZO thin films with $R_{H}=$ $0 \%$ and $10 \%$, respectively. The $\mathrm{O}$ 1s peak was asymmetric and could be resolved into three components, which were located at 530.1 (peak 1), 530.9 (peak 2), and 532.1 (peak 3) $\mathrm{eV}$, respectively. The peak 1 can be attributed to $\mathrm{O}^{2-}$ ions in $\mathrm{Zn}-\mathrm{O}$ bonds. The peaks 2 and 3 are ascribed to oxygen vacancy and loosely bound oxygen species (e.g., $\mathrm{H}_{2} \mathrm{O}, \mathrm{O}_{2}$, and $-\mathrm{OH}$ ) chemisorbed on the surface and grain boundary, respectively $[4,29]$. To compare the characteristic peaks in Figures 3(b) and 3(c), the area ratio of the peak 2 apparently increased from $59 \%$ to $72 \%$, indicating an increase in oxygen vacancies in the films. This result contributes to the increase of the carrier concentration in the $\mathrm{H}_{2}$-doped TZO thin films. The area ratio of the peak 1 decreased from $26 \%$ to $13 \%$, indicating a decrease in the amount of oxygen atoms in a fully stoichiometric $\mathrm{Zn}-\mathrm{O}$ surrounding. It is thought that hydrogen may react with oxygen to form hydroxides in sputtering ambient, causing the lack of oxygen in the films.

Figures 4(a) and 4(b) exhibit the XRD spectra of TZO thin films deposited at different substrate temperatures with $R_{H}=0 \%$ and $10 \%$, respectively. All patterns exhibited only a $\left(\begin{array}{lll}0 & 0 & 2\end{array}\right)$ preferential orientation along the $c$-axis at diffraction angles $(2 \theta)$ near $34^{\circ}$, indicating a hexagonal wurtzite structure, and no characteristic peak of $\mathrm{TiO}_{2}$ was found. The $\left(\begin{array}{lll}0 & 0 & 2\end{array}\right)$ peak intensity increased with increasing $T_{S}$, suggesting that the film crystallinity was enhanced at a high temperature regardless of hydrogen addition. The enhanced film crystallinity is due to an increase in the surface diffusion of the adsorbed species with increasing $T_{S}[4,30]$. Besides, 

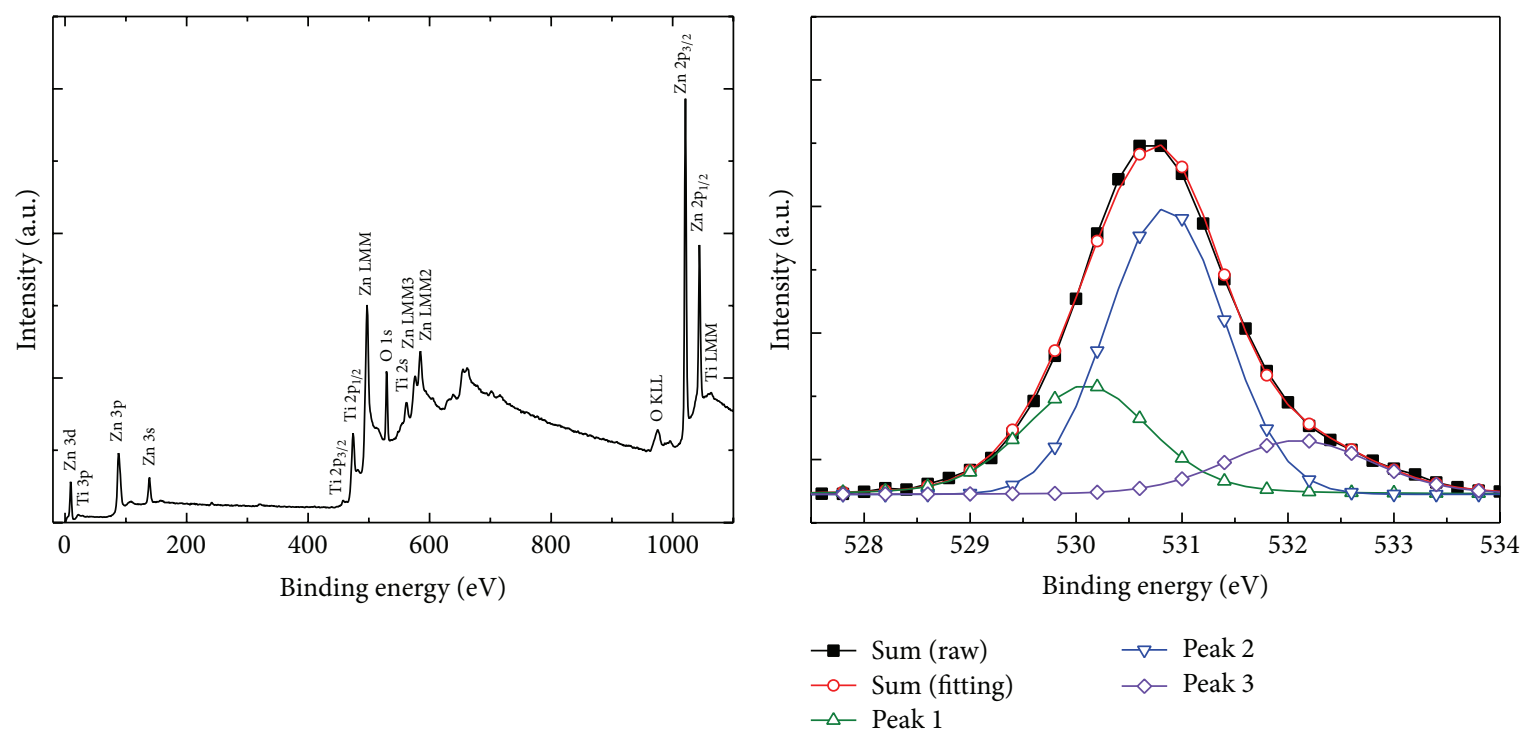

(a)

(b) RT, $0 \%$

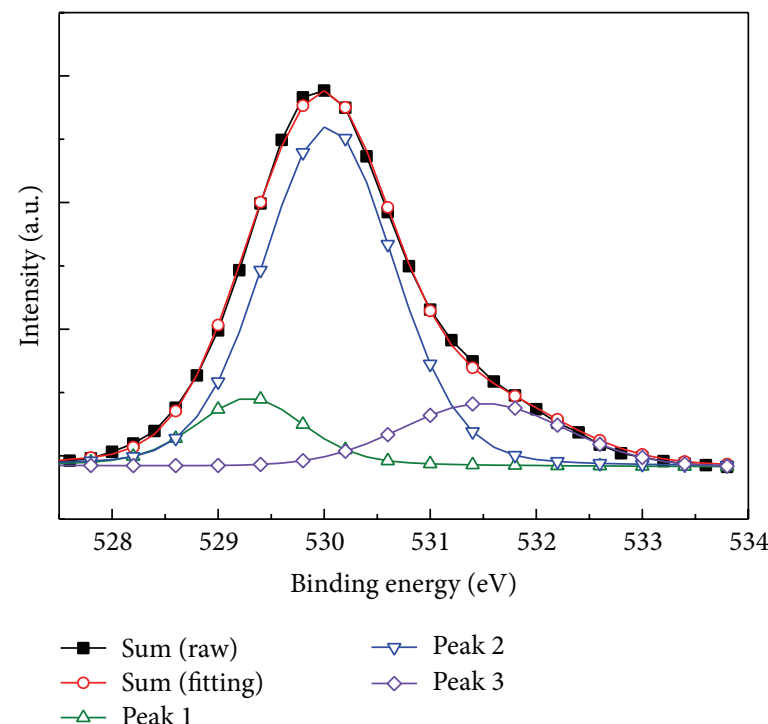

(c) $\mathrm{RT}, 10 \%$

FIgURE 3: (a) XPS spectrum of the RT-deposited TZO thin film with $R_{H}=0 \%$, and the XPS spectra of O 1s for RT-deposited TZO thin films with (b) $R_{H}=0 \%$ and (c) $R_{H}=10 \%$.

the $\left(\begin{array}{lll}0 & 0 & 2\end{array}\right)$ peak positions shifted toward larger diffraction angles as the $T_{S}$ increased from RT to $300^{\circ} \mathrm{C}$. This phenomenon indicates a decrease in the interplanar distance $\left(\mathrm{d}_{002}\right)$, which may be attributed to the fact that more Ti atoms replace substitutional $\mathrm{Zn}$ atoms at a higher $T_{S}$. Since the ionic radius of $\mathrm{Ti}^{4+}(68 \mathrm{pm})$ is smaller than that of $\mathrm{Zn}^{2+}$ $(74 \mathrm{pm})$, the position of the $\left(\begin{array}{ll}0 & 0\end{array}\right)$ peak is expected to shift to a large $2 \theta$ value. Figures $4(\mathrm{c})$ and $4(\mathrm{~d})$ show the XRD spectra of TZO films deposited at RT and $300^{\circ} \mathrm{C}$, respectively, with various $R_{H}$. For the RT depositions (see Figure 3(c)), the increased $R_{H}$ resulted in a noticeable decrease in peak intensity, revealing the fact that hydrogen incorporated into the films and degraded the film crystallinity. Besides, it was found that the $2 \theta$ peak shifted toward lower diffraction angle, indicating an expansion of crystal lattice [17]. It is believed that hydrogen atoms may situate in the center of $\mathrm{Zn}-\mathrm{O}$ bonds, parallel to the $c$-axis which would lead to an increase in the lattice parameter of the films. At the high $T_{S}$ (see Figure $4(\mathrm{~d})$ ), the variations of $\left(\begin{array}{lll}0 & 0 & 2\end{array}\right)$ peak intensities of TZO films with various $R_{H}$ were relatively small as compared to those at RT. The positions of all diffraction peaks did not obviously changed and were at $34.33 \pm 0.03^{\circ}$. It indicated that the structure of the $300^{\circ} \mathrm{C}$-deposited TZO film did not considerably change with increasing $R_{H}$. This result also explains why the electrical properties of the $300^{\circ} \mathrm{C}$-deposited TZO films have no significant variation for different $R_{H}$. 


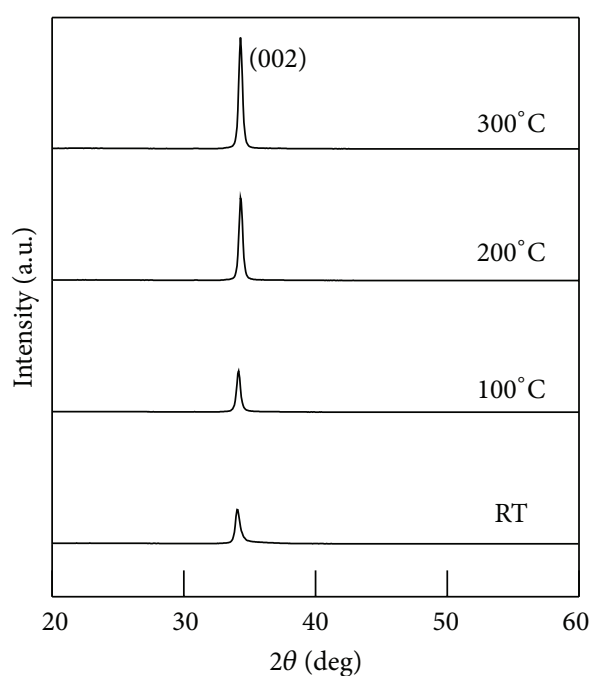

(a) $\mathrm{H}_{2}=0 \%$

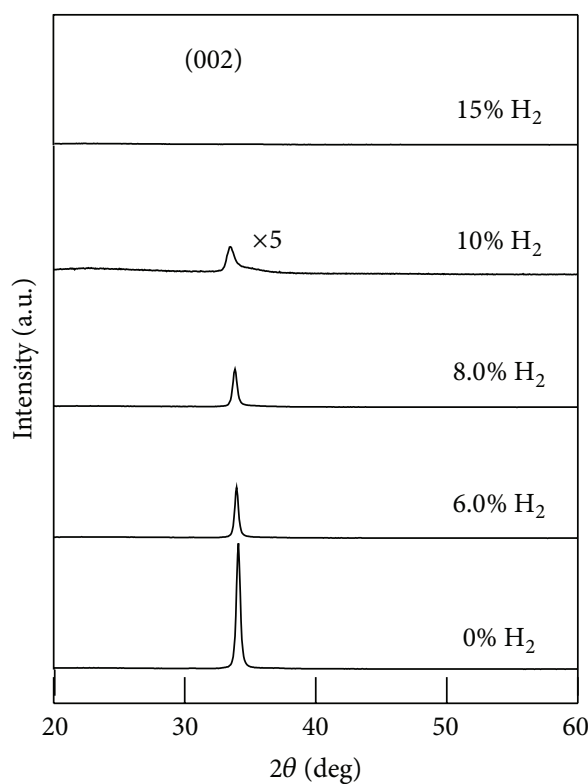

(c) RT

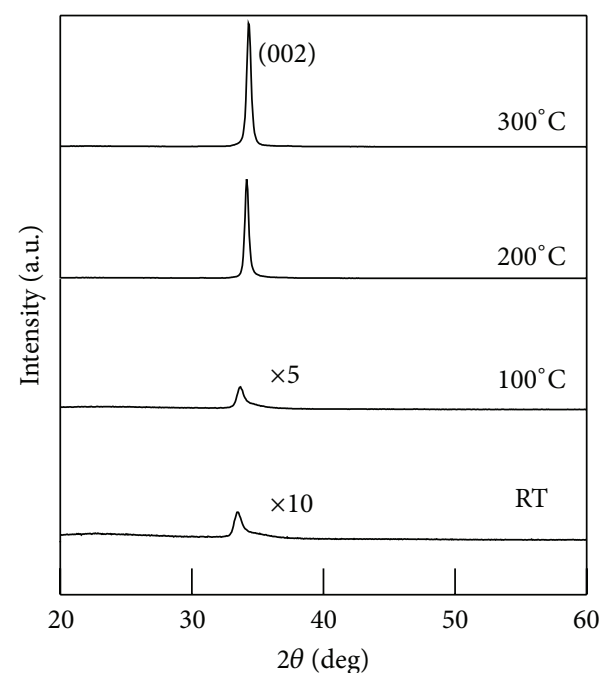

(b) $\mathrm{H}_{2}=10 \%$

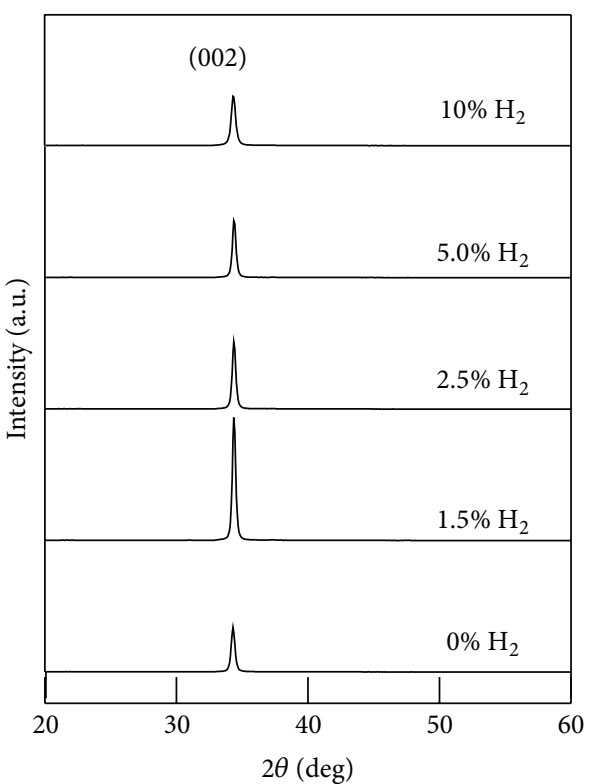

(d) $300^{\circ} \mathrm{C}$

FIGURE 4: XRD spectra of TZO thin films deposited with $\mathrm{H}_{2} /\left(\mathrm{Ar}+\mathrm{H}_{2}\right)$ flow ratio of (a) $0 \%$ and (b) $10 \%$ at various substrate temperatures and with various $\mathrm{H}_{2} /\left(\mathrm{Ar}+\mathrm{H}_{2}\right)$ flow ratios at (c) $\mathrm{RT}$ and (d) $300^{\circ} \mathrm{C}$.

Figure 5(a) shows the full-width at half-maximum (FWHM) and grain size of TZO thin films deposited with $R_{H}=0$ and $10 \%$ at various $T_{S}$. The grain size was estimated with Scherrer's formula [31]:

$$
D=\frac{0.94 \lambda}{\beta \cos \theta},
$$

where $\lambda=0.154056 \mathrm{~nm}, D$ is grain size, and $\beta$ is FWHM. The FWHM decreased with the increase of the $T_{S}$ regardless of hydrogen content, indicating the increase of the grain size. Lin et al. also reported the similar trend in the $50-200^{\circ} \mathrm{C}$ deposited AZO films [32]. Besides, the nonhydrogenated TZO films exhibited larger grain sizes than those deposited with $R_{H}=10 \%$ regardless of $T_{S}$. Figure 5(b) shows the FWHM and grain size of TZO films deposited at RT and $300^{\circ} \mathrm{C}$ with various $R_{H}$. A small addition of hydrogen could increase the grain size, while excess hydrogen would deteriorate film crystallinity and thus decrease the grain size.

Figures 6(a)-6(f) display the $45^{\circ}$-tilted FE-SEM images of TZO thin films deposited at RT and $300^{\circ} \mathrm{C}$ with $R_{H}=$ $0,5 \%$, and $10 \%$. The cross-section views of TZO films showed a well-defined columnar structure. Comparing the RT and $300^{\circ} \mathrm{C}$-deposited films, it was found that the latter has a smoother surface morphology and a denser columnar structure than the former. This is due to the fact that the high substrate temperature increases the energy of adsorbed 


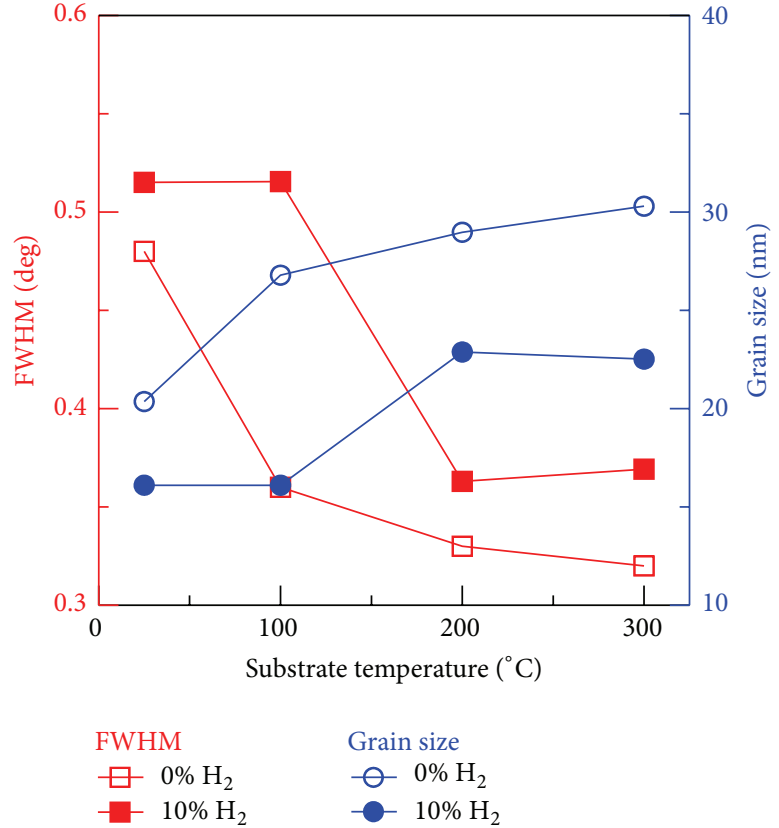

(a)

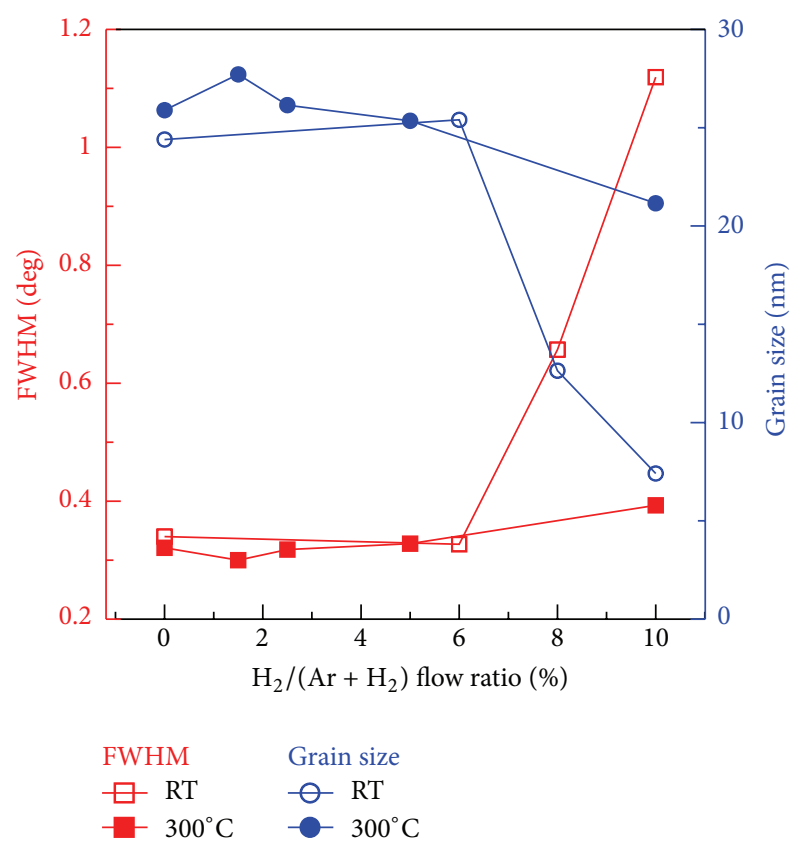

(b)

FIgURE 5: Full-width at half-maximum (FWHM) and grain size of TZO thin films deposited (a) with $\mathrm{H}_{2} /\left(\mathrm{Ar}+\mathrm{H}_{2}\right)$ flow ratio of 0 and $10 \%$ at various substrate temperatures and (b) with various $\mathrm{H}_{2} /\left(\mathrm{Ar}+\mathrm{H}_{2}\right)$ flow ratios at $\mathrm{RT}$ and $300^{\circ} \mathrm{C}$.

ions and thus improves the structural properties of TZO films, which is consistent with the XRD results shown in Figure 4. Comparing the films with different $R_{H}$, the surface morphology of TZO films became spherical shaped domains and rough with increasing $R_{H}$. Addonizio et al. and Lee also reported that the surface of AZO films became rough as hydrogen added in sputtering gas $[33,34]$. However, Gottardi et al. indicated that the $\mathrm{ZnO}$ films deposited in pure $\mathrm{Ar}$ ambient showed a rougher surface than that prepared in $\mathrm{Ar}+$ $\mathrm{H}_{2}(10 \%)$ ambient. In this work, the estimated mean-free path of energetic particles at RT would be around $1.6 \mathrm{~cm}$, which is smaller than the working distance $(10 \mathrm{~cm})$. Hydrogen dilution in sputtering gas may decrease the scattering cross-section and hence increase the energy of the sputtering particles. Besides, hydrogen has strong reduction and etching effect on film surface. It is believed that enhanced $\mathrm{Ar}^{+}$bombardment and strong reduction and etching effect of hydrogen on film surfaces disturbs the grain growth and results in the rough surface. The AFM images of TZO thin films (see Figure 7) exhibited that the RMS roughness increased from 1.99 to $4.79 \mathrm{~nm}$ as $R_{H}$ increased from 0 to $7.5 \%$.

Figures $8(\mathrm{a})$ and $8(\mathrm{~b})$ show the optical transmittance spectra of TZO thin films prepared with various $R_{H}$ at $T_{S}=$ $\mathrm{RT}$ and $300^{\circ} \mathrm{C}$, respectively, in the wavelength region of 220 $2500 \mathrm{~nm}$. All TZO films showed sharp absorption edges in the ultraviolet range and a decreased transmittance with $R_{H}$ in the near infrared (NIR) region. The decreasing transmittance in the NIR region with wavelength can be explained by the classical Drude model [35], which indicates that the decrease of transmittance is attributed to free carrier absorption that increases with the hydrogen incorporation. Variations of the average visible transmittance $\left(T_{\text {ave }}\right)$ (including glass substrate) in the 400-750 nm region are shown in Figure 9(a). The $T_{\text {ave }}$ slightly decreased from $84.0 \%$ to $81.7 \%$ as the $R_{H}$ varied from 0 to $10 \%$ for the RT-deposited films, while $T_{\text {ave }}$ remained around $84.7 \% \pm 0.5 \%$ for those prepared at $300^{\circ} \mathrm{C}$. Furthermore, $T_{\text {ave }}$ significantly decreased to $70.5 \%$ as for the film with very high $R_{H}(20 \%)$. The lower visible transmittance at the lower $T_{S}$ can be attributed to the enhancement of scattering and absorption of light due to worse crystallinity and a rougher film surface, as the XRD and SEM analyses show. This similar behavior on AZO thin films was reported by our group and Liu et al. [4,27]. The findings indicated that the AZO thin film prepared with relative high $\mathrm{H}_{2}$-flow rate showed bad transparency due to the increase of intergranular zinc atoms caused by hydrogen doping.

Figure $9(\mathrm{~b})$ presents the optical bandgap $\left(E_{g}\right)$ of TZO thin films prepared with different $R_{H}$ at the $T_{S}=\mathrm{RT}$ and $300^{\circ} \mathrm{C}$. The $E_{g}$ was determined by taking the energy corresponding to the maximum of $d \alpha^{2} / d(h \nu)$, where $\alpha$ is the optical absorption coefficient calculated from the transmittance spectra and $h v$ is the photon energy [36]. The calculated $E_{g}$ of the RTprepared films increased from 3.29 to $3.61 \mathrm{eV}$ as $R_{H}$ increased from 0 to $10 \%$ and then decreased to $3.57 \mathrm{eV}$ for a further increase in $R_{H}(20 \%)$. The $E_{g}$ broadening phenomenon is known as the Burstein-Moss effect, which specifies the Fermi level inside the conduction band that moves upward with increasing carrier concentration due to the filling of conduction band by the increase of electron carriers [37]. The film deposited at the higher temperature $\left(300^{\circ} \mathrm{C}\right)$ exhibited 


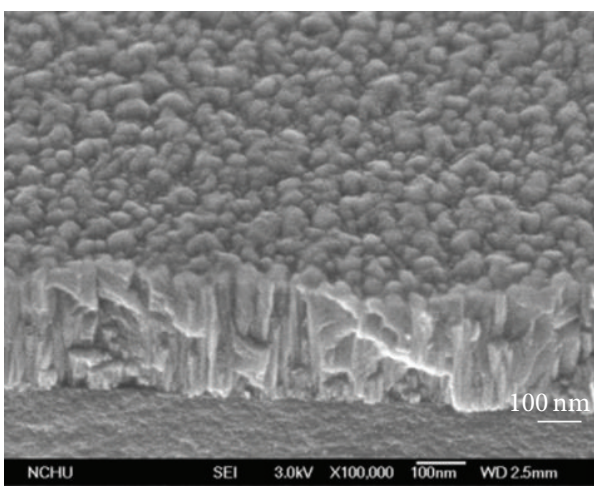

(a) RT, $R_{H}=0 \%$

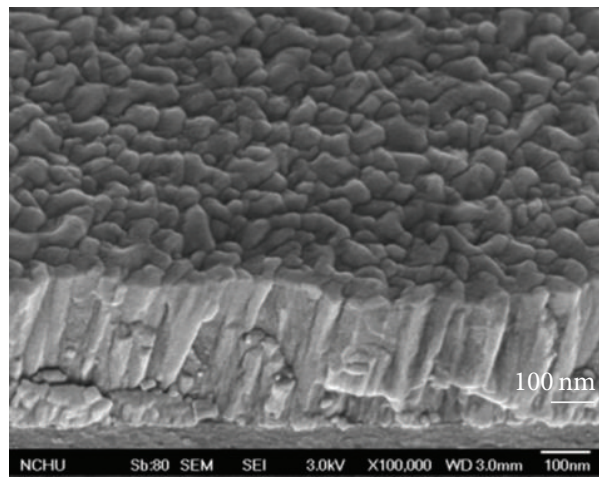

(c) RT, $R_{H}=5 \%$

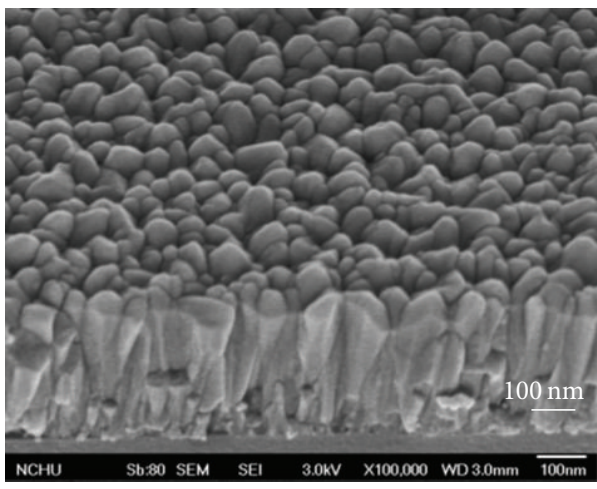

(e) RT, $R_{H}=10 \%$

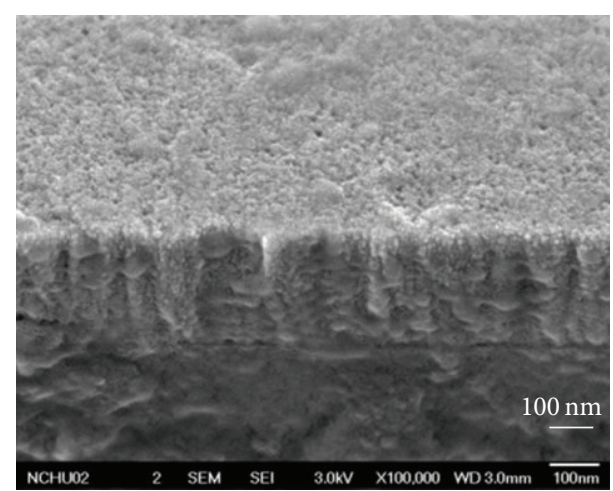

(b) $300^{\circ} \mathrm{C}, R_{H}=0 \%$

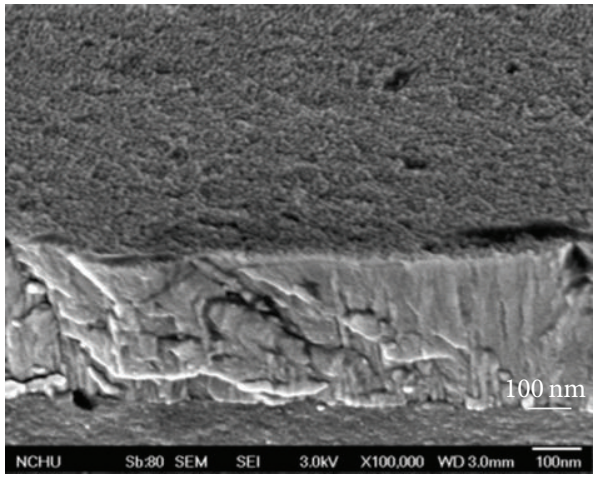

(d) $300^{\circ} \mathrm{C}, R_{H}=5 \%$

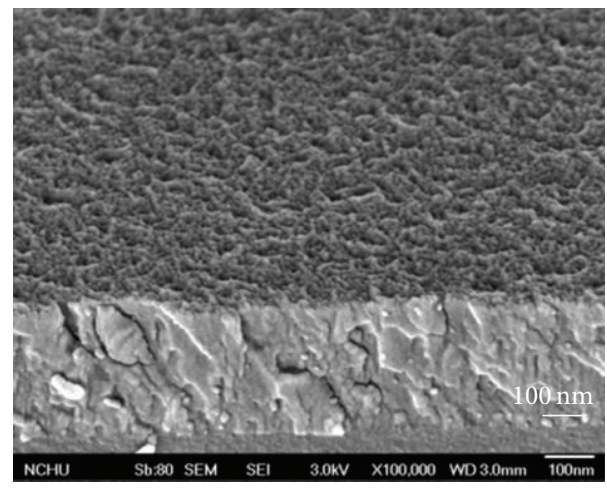

(f) $300^{\circ} \mathrm{C}, R_{H}=10 \%$

Figure 6: FE-SEM images of TZO thin films deposited at RT and $300^{\circ} \mathrm{C}$ with $R_{H}=0,5 \%$, and $10 \%$.

a weak dependence of $E_{g}$ on $R_{H}$ and their $E_{g}$ increased from 3.43 to $3.53 \mathrm{eV}$ as the $R_{H}$ increased from 0 to $10 \%$. This weak dependent for the $300^{\circ} \mathrm{C}$-deposited films is attributed to the behavior that less hydrogen atoms are doped in the TZO films.

The transparent conducting thin films must have low resistivity and high optical transparency for the application of solar cells. A way for evaluating this compromise is by means of figure of merit (FOM). FOM defined by Haacke is one of the important indices for judging the effectiveness of different processes. FOM is defined by [38]

$$
\operatorname{FOM}\left(\Omega^{-1}\right)=\frac{T^{10}}{R_{S}}
$$

where $T$ is the average visible transmittance and $R_{S}$ is the sheet resistance of films. Figure 10 shows the FOM of TZO films deposited with different substrate temperatures and $\mathrm{H}_{2} /\left(\mathrm{Ar}+\mathrm{H}_{2}\right)$ flow ratios. At the high $T_{S}\left(200-300^{\circ} \mathrm{C}\right)$, FOM slightly increased for a small addition of $\mathrm{H}_{2}$ and then decreased as $R_{H}$ went beyond $2.5 \%$. By contrast, FOM of the low $T_{S}\left(\mathrm{RT}-100^{\circ} \mathrm{C}\right)$ prepared films significantly increased over two orders of magnitude with increasing $R_{H}$ and the highest FOM, $4.74 \times 10^{-3} \Omega^{-1}$, was achieved for the films prepared at $100^{\circ} \mathrm{C}$ with $R_{H}=7.5 \%$. These results indicate that the in situ hydrogen doping effectively improves electrooptical properties of TZO thin films and the effectiveness of hydrogen doping is strongly dependent on substrate temperature and $\mathrm{H}_{2} /\left(\mathrm{Ar}+\mathrm{H}_{2}\right)$ flow ratio. 


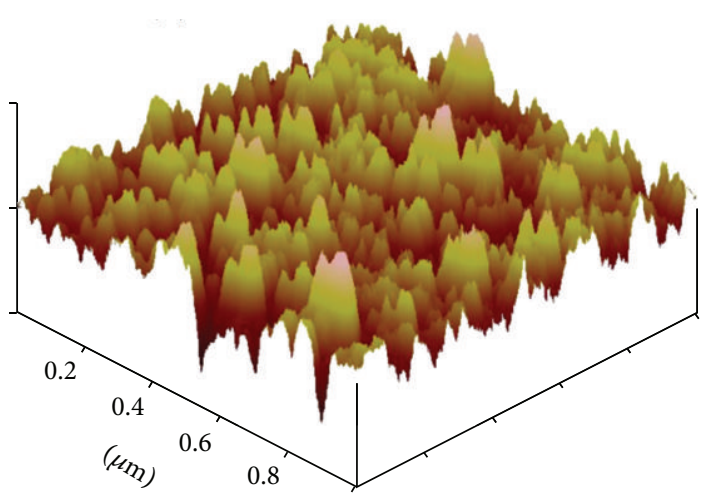

(a) $R_{H}=0$

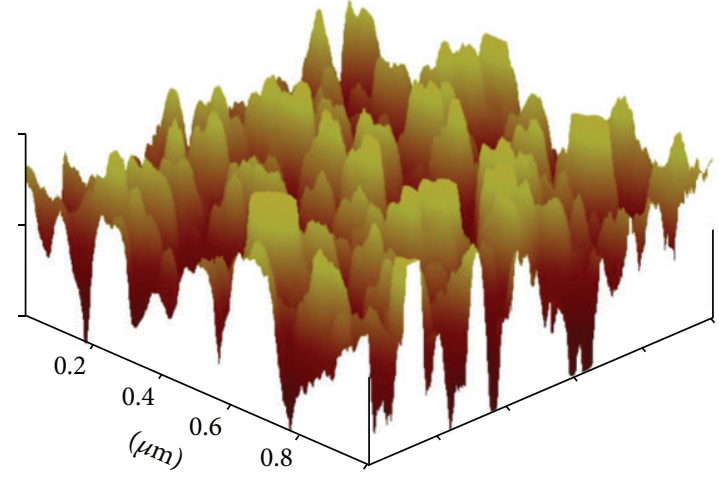

(b) $R_{H}=7.5 \%$

FIgURE 7: AFM images of TZO thin films $(1 \mu \mathrm{m} \times 1 \mu \mathrm{m}$ area $)$ deposited at $100^{\circ} \mathrm{C}$ with $R_{H}=0$ and $7.5 \%$.

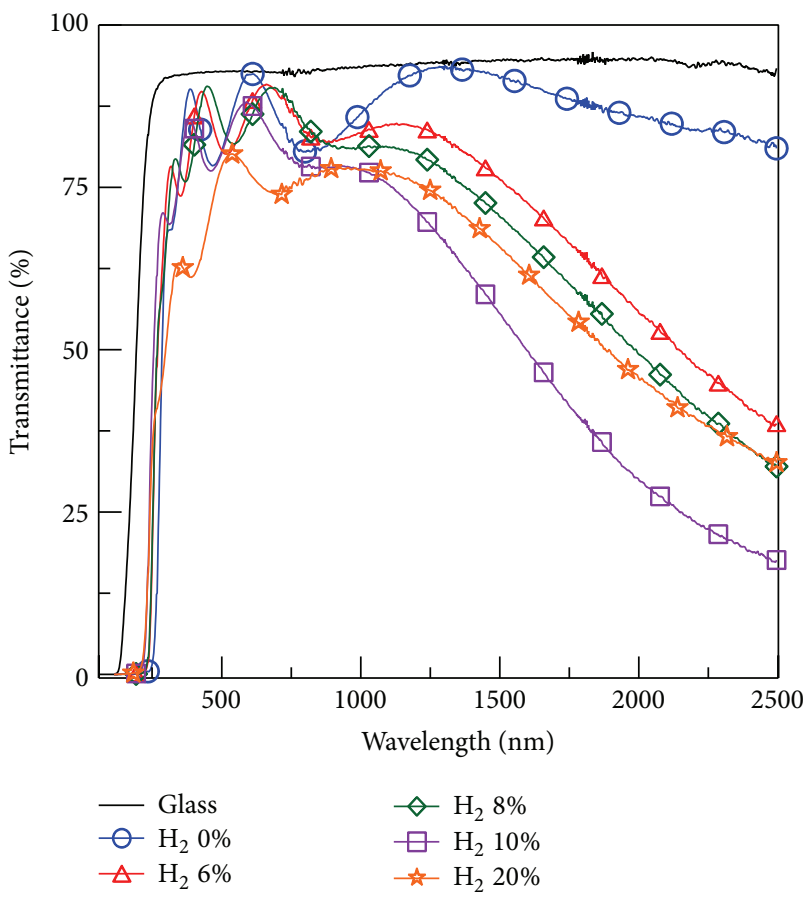

(a) RT

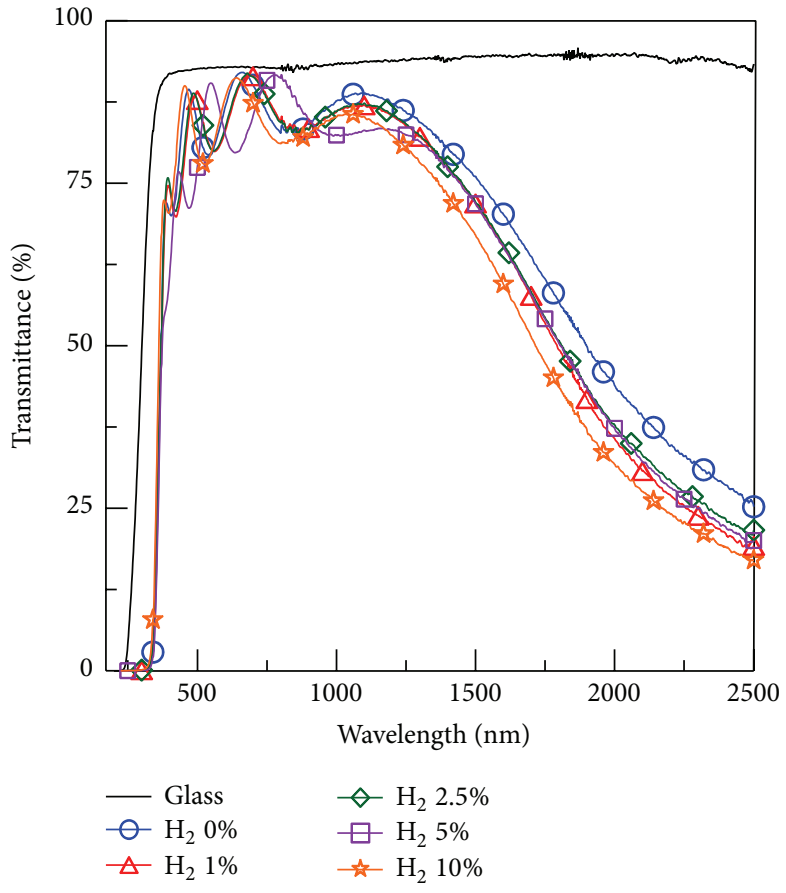

(b) $300^{\circ} \mathrm{C}$

FIGURE 8: Optical transmittance spectra of TZO thin films prepared with various $\mathrm{H}_{2} /\left(\mathrm{Ar}+\mathrm{H}_{2}\right)$ flow ratios at substrate temperatures of (a) $\mathrm{RT}$ and (b) $300^{\circ} \mathrm{C}$ in the wavelength region of $220-2500 \mathrm{~nm}$.

\section{Conclusions}

The hydrogen and titanium codoped $\mathrm{ZnO}$ thin films were fabricated by sputtering of a $\mathrm{ZnO}$ target containing $1.5 \mathrm{wt} \% \mathrm{TiO}_{2}$ in $\mathrm{Ar} / \mathrm{H}_{2}$ gas mixtures at substrate temperatures of RT- $300^{\circ} \mathrm{C}$ on glass substrates. The XRD analysis showed that all of TZO films exhibit a (002) preferential orientation along the $c$-axis at $2 \theta \sim 34^{\circ}$. The (002) peak shifted toward the large diffraction angles with increasing substrate temperature. The excess hydrogen addition in the TZO films resulted in the decrease of the (002) peak intensity and the left-shift of the peak position, revealing poor crystallinity due to that the hydrogen atoms might insert into the $\mathrm{Zn}-\mathrm{O}$ bonds and extract oxygen from the film. The hydrogen incorporation in the TZO films improved the electrical and optical properties and the extent of improvement was dependent on the $\mathrm{H}_{2} /\left(\mathrm{Ar}+\mathrm{H}_{2}\right)$ flow ratio along with the substrate temperature. The calculated Haacke's figure of merits showed that the optimized TZO films were achieved at the substrate temperature of $100^{\circ} \mathrm{C}$ and the $\mathrm{H}_{2} /\left(\mathrm{Ar}+\mathrm{H}_{2}\right)$ flow ratio of $7.5 \%$ and accompanied by the resistivity of $9.2 \times 10^{-4} \Omega$-cm and the average transmittance more than $80 \%$. Excess hydrogen content deteriorated the electrooptical properties of the TZO films due to the poor crystallinity, the rough film surface, and the more defects 


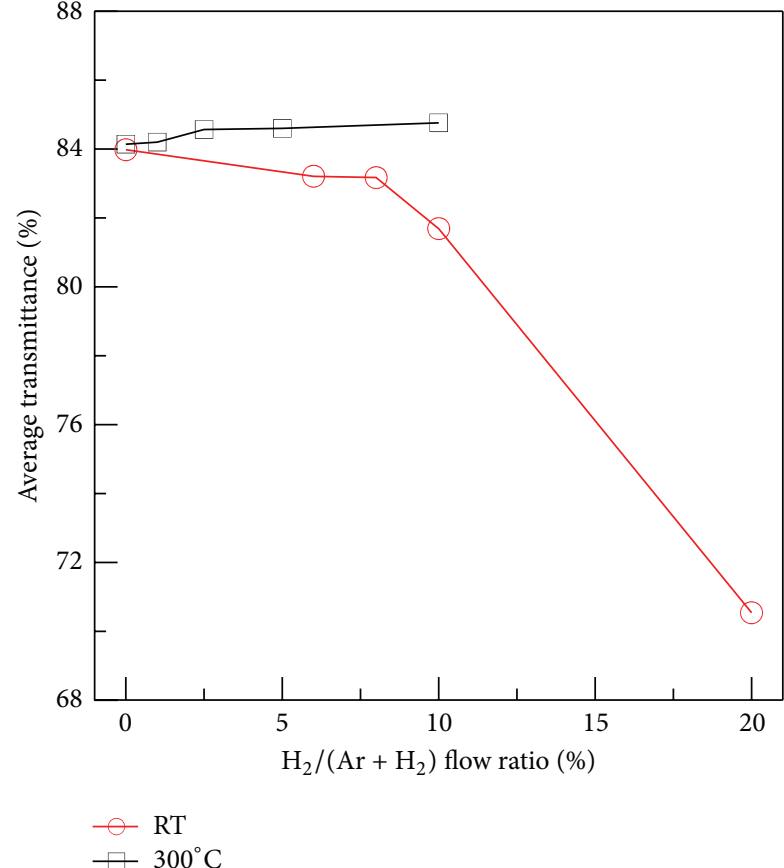

(a)

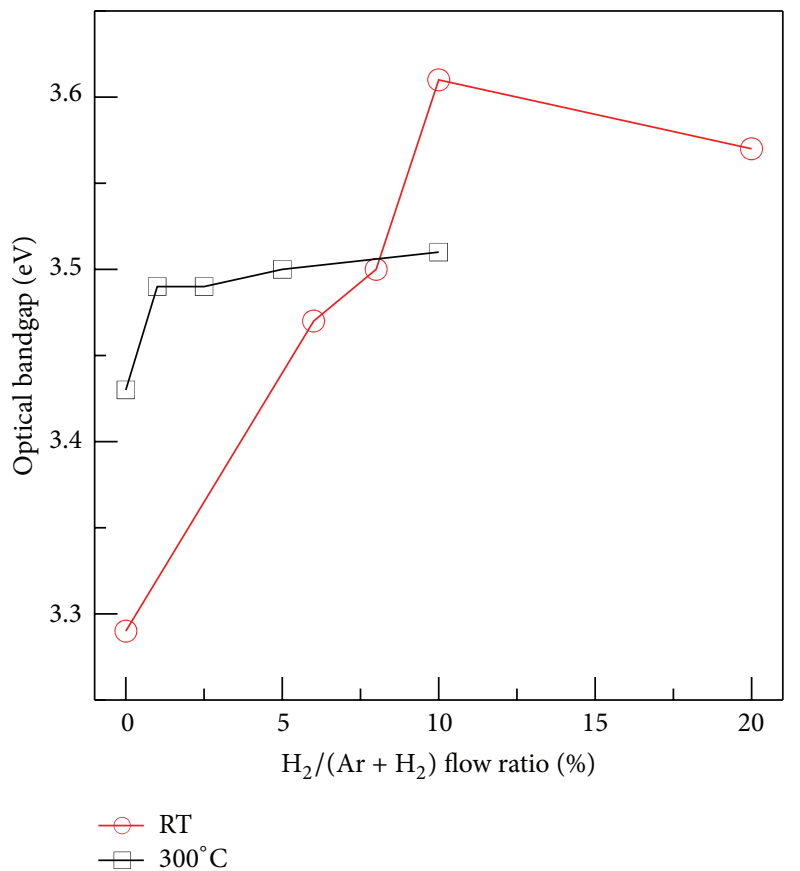

(b)

FIgURE 9: (a) Average transmittance and (b) optical bandgap of TZO thin films with different $\mathrm{H}_{2} /\left(\mathrm{Ar}+\mathrm{H}_{2}\right)$ flow ratios.

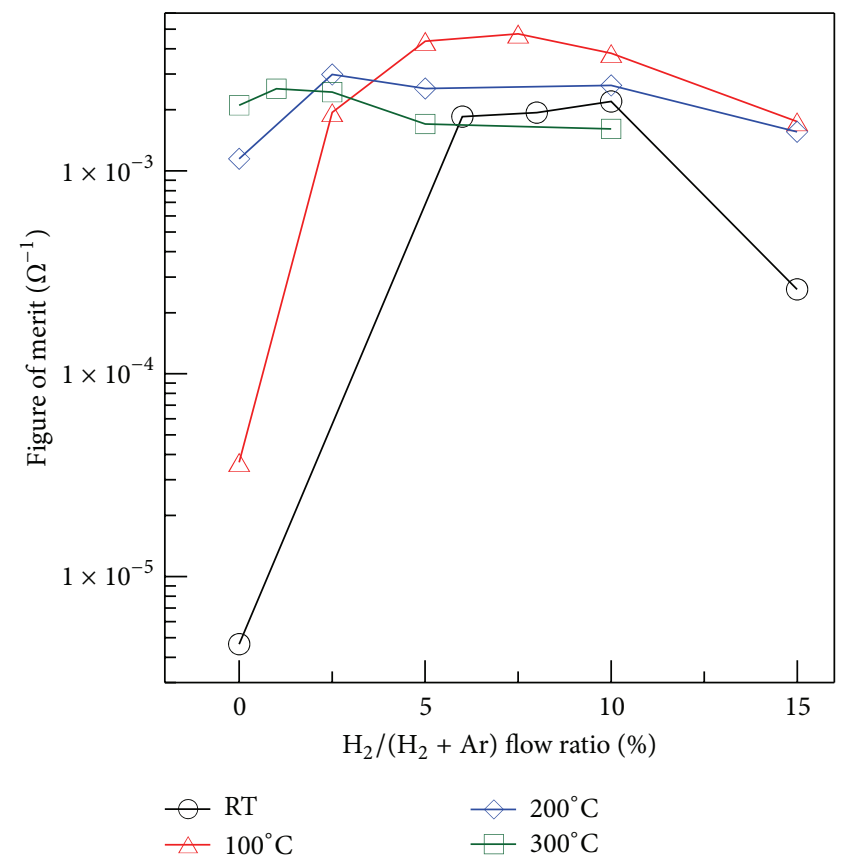

FIGURE 10: Figure of merit of TZO thin films deposited with different substrate temperatures and $\mathrm{H}_{2} /\left(\mathrm{Ar}+\mathrm{H}_{2}\right)$ flow ratios.

in the films. The developed hydrogen and titanium codoped $\mathrm{ZnO}$ thin films have potential for transparent conducting electrode applications.

\section{Conflict of Interests}

The authors declare that there is no conflict of interests regarding to the publication of this paper.

\section{Acknowledgments}

This work has received financial support from the National Science Council of the Republic of China (Taiwan) under Contract no. NSC 101-2221-E-005-065. Authors thank Dr. Chia-Cheng Huang and Dr. Hung-Peng Chang for performing some measurements.

\section{References}

[1] H. C. Weller, R. H. Mauch, and G. H. Bauer, "Studies on the interface between novel type $\mathrm{ZnO}$ and $\mathrm{p}-\mathrm{a}-\mathrm{SiC}: \mathrm{H}$ in $1.5 \mathrm{eV}$ aSiGe:H pin diodes in comparison to $\mathrm{SnO}_{x}$ and ITO," Solar Energy Materials and Solar Cells, vol. 27, no. 3, pp. 217-231, 1992.

[2] D. S. Ginley and C. Bright, "Transparent conducting oxides," MRS Bulletin, vol. 25, no. 8, pp. 15-18, 2000.

[3] T. Minami and T. Miyata, "Present status and future prospects for development of non- or reduced-indium transparent conducting oxide thin films," Thin Solid Films, vol. 517, no. 4, pp. 1474-1477, 2008.

[4] F.-H. Wang, H.-P. Chang, C.-C. Tseng, and C.-C. Huang, "Effects of $\mathrm{H}_{2}$ plasma treatment on properties of $\mathrm{ZnO}$ :Al thin films prepared by RF magnetron sputtering," Surface and Coatings Technology, vol. 205, no. 23-24, pp. 5269-5277, 2011.

[5] P. K. Song, M. Watanabe, M. Kon, A. Mitsui, and Y. Shigesato, "Electrical and optical properties of gallium-doped zinc oxide 
films deposited by dc magnetron sputtering," Thin Solid Films, vol. 411, no. 1, pp. 82-86, 2002.

[6] L. Cao, L. Zhu, J. Jiang, R. Zhao, Z. Ye, and B. Zhao, "Highly transparent and conducting fluorine-doped $\mathrm{ZnO}$ thin films prepared by pulsed laser deposition," Solar Energy Materials and Solar Cells, vol. 95, no. 3, pp. 894-898, 2011.

[7] S. H. Park, J. B. Park, and P. K. Song, "Characteristics of Aldoped, Ga-doped and In-doped zinc-oxide films as transparent conducting electrodes in organic light-emitting diodes," Current Applied Physics, vol. 10, no. 3, supplement, pp. S488-S490, 2010.

[8] T. Prasada Rao and M. C. Santhosh Kumar, "Physical properties of Ga-doped $\mathrm{ZnO}$ thin films by spray pyrolysis," Journal of Alloys and Compounds, vol. 506, no. 2, pp. 788-793, 2010.

[9] S. S. Lin, J. L. Huang, and P. Šajgalik, "The properties of Ti-doped $\mathrm{ZnO}$ films deposited by simultaneous RF and DC magnetron sputtering," Surface and Coatings Technology, vol. 191, no. 2-3, pp. 286-292, 2005.

[10] J. L. Chung, J. C. Chen, and C. J. Tseng, "The influence of titanium on the properties of zinc oxide films deposited by radio frequency magnetron sputtering," Applied Surface Science, vol. 254, no. 9, pp. 2615-2620, 2008.

[11] H.-P. Chang, F.-H. Wang, J.-C. Chao, C.-C. Huang, and H.-W. Liu, "Effects of thickness and annealing on the properties of Tidoped $\mathrm{ZnO}$ films by radio frequency magnetron sputtering," Current Applied Physics, vol. 11, no. 1, supplement, pp. S185S190, 2011.

[12] J. N. Duenow, T. A. Gessert, D. M. Wood, D. L. Young, and T. J. Coutts, "Effects of hydrogen content in sputtering ambient on ZnO:Al electrical properties," Journal of Non-Crystalline Solids, vol. 354, no. 19-25, pp. 2787-2790, 2008.

[13] Y. R. Park, J. Kim, and Y. S. Kim, "Effect of hydrogen doping in $\mathrm{ZnO}$ thin films by pulsed DC magnetron sputtering," Applied Surface Science, vol. 255, no. 22, pp. 9010-9014, 2009.

[14] J. Hu and R. G. Gordon, "Textured aluminum-doped zinc oxide thin films from atmospheric pressure chemical-vapor deposition," Journal of Applied Physics, vol. 71, pp. 880-890, 1992.

[15] F. Furusaki, J. Takahashi, and K. Kodaira, "Preparation of ITO thin films by sol-gel method," Journal of the Ceramic Society of Japan, vol. 102, no. 1182, pp. 200-205, 1994.

[16] F. H. Wang, H. P. Chang, and J. C. Chao, "Improved properties of Ti-doped $\mathrm{ZnO}$ thin films by hydrogen plasma treatment," Thin Solid Films, vol. 519, no. 15, pp. 5178-5182, 2011.

[17] C. G. van de Walle, "Hydrogen as a cause of doping in zinc oxide," Physical Review Letters, vol. 85, no. 5, pp. 1012-1015, 2000.

[18] C. G. van de Walle and J. Neugebauer, "Universal alignment of hydrogen levels in semiconductors, insulators and solutions," Nature, vol. 423, no. 6940, pp. 626-628, 2003.

[19] S. H. Lee, T. S. Lee, K. S. Lee, B. Cheong, Y. D. Kim, and W. M. Kim, "Characteristics of hydrogen co-doped $\mathrm{ZnO}$ : Al thin films," Journal of Physics D: Applied Physics, vol. 41, no. 9, Article ID 095303, 2008.

[20] R. Das and S. Ray, "Zinc oxide-a transparent, conducting IR-reflector prepared by rf-magnetron sputtering," Journal of Physics D: Applied Physics, vol. 36, no. 2, pp. 152-155, 2003.

[21] A. Bikowski and K. Ellmer, "Electrical transport in hydrogenaluminium Co-doped $\mathrm{ZnO}$ and $\mathrm{Zn}_{1-x} \mathrm{Mg}_{x} \mathrm{O}$ films: relation to film structure and composition," Journal of Applied Physics, vol. 113, no. 5, Article ID 053710, 2013.
[22] D.-H. Kim, S.-H. Lee, G.-H. Lee et al., "Effects of deposition temperature on the effectiveness of hydrogen doping in Gadoped $\mathrm{ZnO}$ thin films," Journal of Applied Physics, vol. 108, no. 2, Article ID 023520, 2010.

[23] W. F. Liu, G. T. Du, Y. F. Sun et al., "Effects of hydrogen flux on the properties of Al-doped $\mathrm{ZnO}$ films sputtered in $\mathrm{Ar}+\mathrm{H}_{2}$ ambient at low temperature," Applied Surface Science, vol. 253, no. 6, pp. 2999-3003, 2007.

[24] J. F. Chang, W. C. Lin, and M. H. Hon, "Effects of post-annealing on the structure and properties of Al-doped zinc oxide films," Applied Surface Science, vol. 183, no. 1-2, pp. 18-25, 2001.

[25] R. B. H. Tahar and N. B. H. Tahar, "Mechanism of carrier transport in aluminum-doped zinc oxide," Journal of Applied Physics, vol. 92, no. 8, pp. 4498-4501, 2002.

[26] S. S. Lin, J. L. Huang, and P. Šajgalik, "Effects of substrate temperature on the properties of heavily Al-doped $\mathrm{ZnO}$ films by simultaneous r.f. and d.c. magnetron sputtering," Surface and Coatings Technology, vol. 190, no. 1, pp. 39-47, 2005.

[27] W. F. Liu, G. T. Du, Y. F. Sun et al., "Al-doped ZnO thin films deposited by reactive frequency magnetron sputtering: $\mathrm{H}_{2}$-induced property changes," Thin Solid Films, vol. 515, no. 5, pp. 3057-3060, 2007.

[28] T. Minami, H. Sato, K. Ohashi, T. Tomofuji, and S. Takata, "Conduction mechanism of highly conductive and transparent zinc oxide thin films prepared by magnetron sputtering," Journal of Crystal Growth, vol. 117, no. 1-4, pp. 370-374, 1992.

[29] M. Chen, X. Wang, Y. H. Yu et al., "X-ray photoelectron spectroscopy and auger electron spectroscopy studies of Aldoped ZnO films," Applied Surface Science, vol. 158, no. 1-2, pp. 134-140, 2000.

[30] K. H. Kim, K. C. Park, and D. Y. Ma, "Structural, electrical and optical properties of aluminum doped zinc oxide films prepared by radio frequency magnetron sputtering," Journal of Applied Physics, vol. 81, no. 12, pp. 7764-7772, 1997.

[31] B. D. Cullity and S. R. Stock, Elements of X-Ray Diffraction, Prentice Hall, 3rd edition, 2001.

[32] S.-S. Lin, J.-L. Huang, and D.-F. Lii, "Effect of substrate temperature on the properties of Ti-doped $\mathrm{ZnO}$ films by simultaneous rf and dc magnetron sputtering," Materials Chemistry and Physics, vol. 90, no. 1, pp. 22-30, 2005.

[33] M. L. Addonizio, A. Antonaia, G. Cantele, and C. Privato, "Transport mechanisms of RF sputtered Al-doped $\mathrm{ZnO}$ films by $\mathrm{H}_{2}$ process gas dilution," Thin Solid Films, vol. 349, no. 1, pp. 93-99, 1999.

[34] J.-H. Lee, "Effects of hydrogen incorporation and heat treatment on the properties of $\mathrm{ZnO}: \mathrm{Al}$ films deposited on polymer substrate for flexible solar cell applications," Current Applied Physics, vol. 10, no. 3, supplement, pp. S515-S519, 2010.

[35] H. L. Hartnagel, A. L. Dawar, A. K. Jain, and C. Jagadish, in Semiconducting Transparent Thin Films, Institute of Physics Publishing, Bristol, UK, 1st edition, 1995.

[36] M. Purica, E. Budianu, E. Rusu, M. Danila, and R. Gavrila, "Optical and structural investigation of $\mathrm{ZnO}$ thin films prepared by chemical vapor deposition (CVD)," Thin Solid Films, vol. 403-404, pp. 485-488, 2002.

[37] E. Burstein, "Anomalous optical absorption limit in InSb," Physical Review, vol. 93, no. 3, pp. 632-633, 1954.

[38] G. Haacke, "New figure of merit for transparent conductors," Journal of Applied Physics, vol. 47, no. 9, pp. 4086-4089, 1976. 

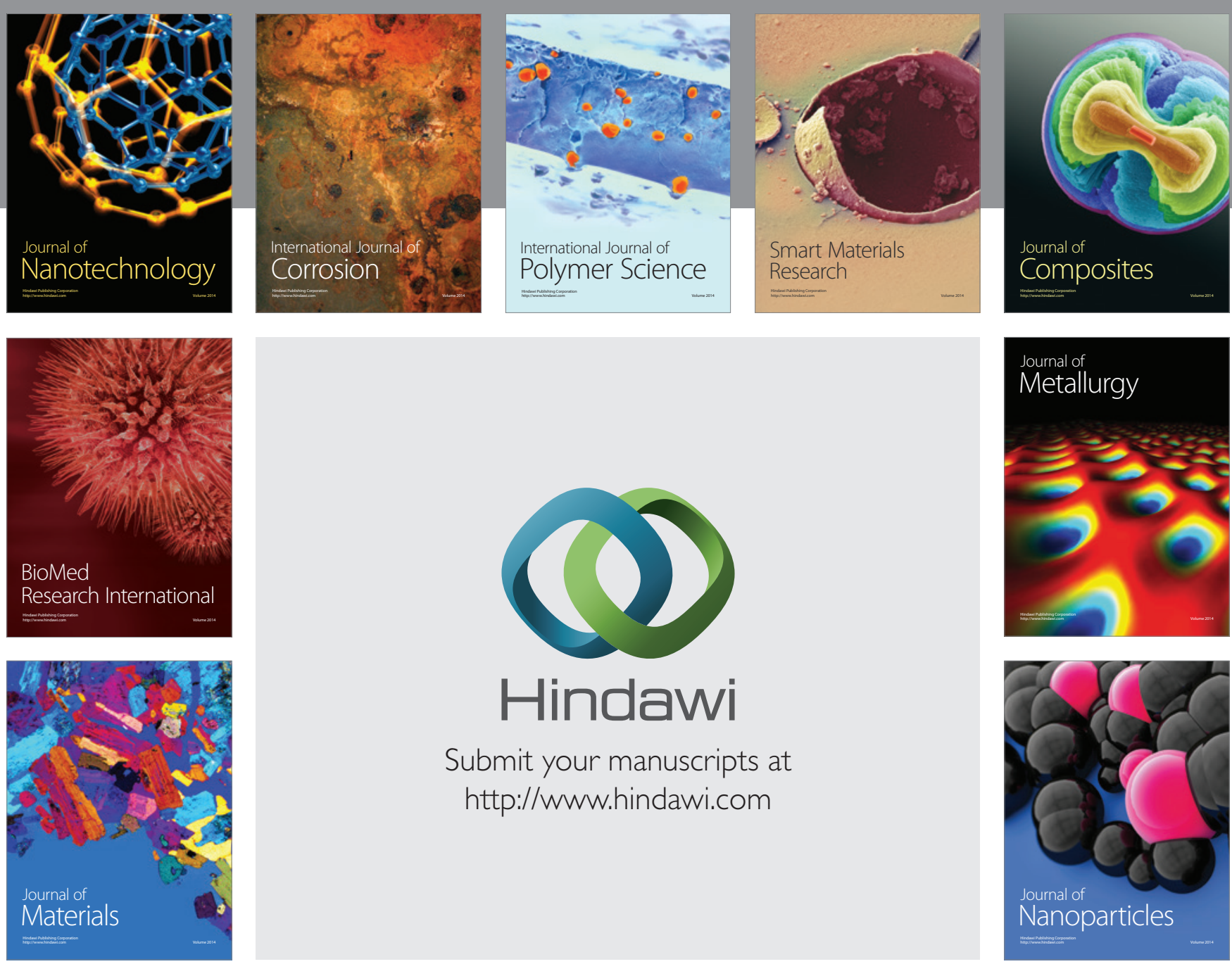

Submit your manuscripts at http://www.hindawi.com
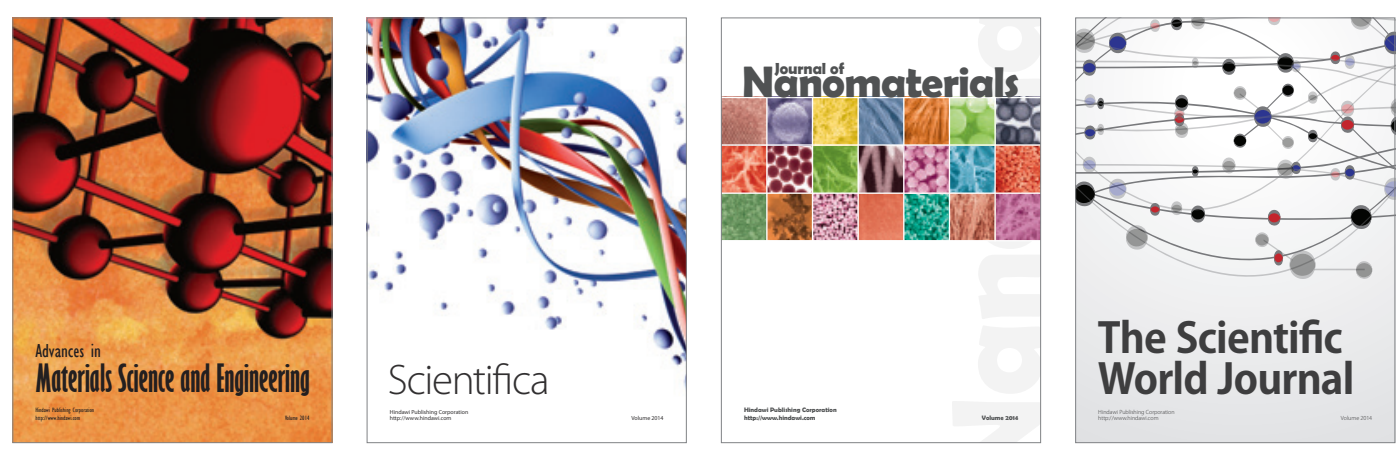

\section{The Scientific World Journal}
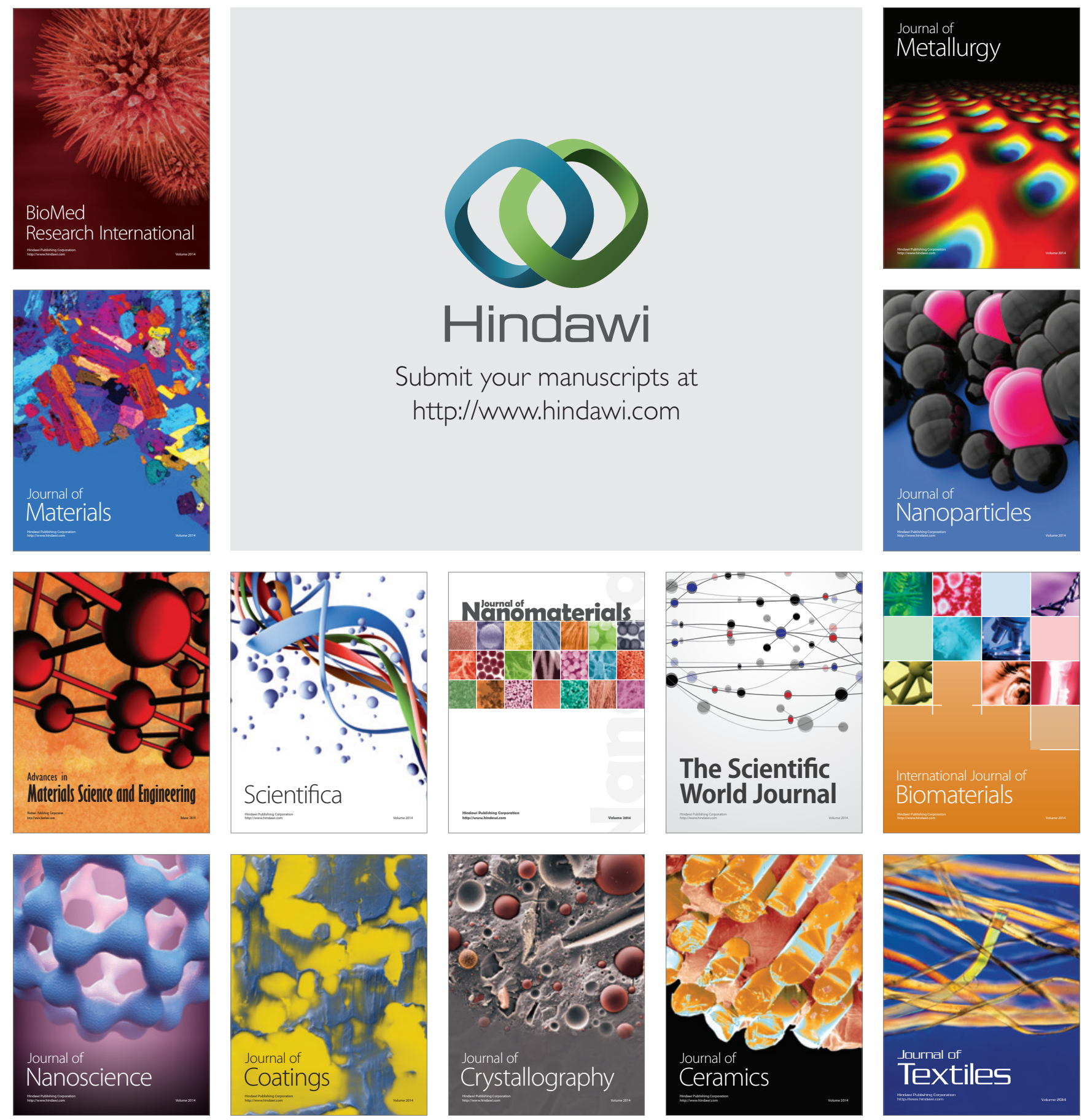